\title{
Co-infection and localization of secondary symbionts in two whitefly species
}

\author{
Marisa Skaljac' ${ }^{1}$, Katja Zanic'1, Smiljana Goreta Ban'1, Svetlana Kontsedalov² and Murad Ghanim*2
}

\begin{abstract}
Background: Whiteflies are cosmopolitan phloem-feeding pests that cause serious damage to many crops worldwide due to direct feeding and vectoring of many plant viruses. The sweetpotato whitefly Bemisia tabaci (Gennadius) and the greenhouse whitefly Trialeurodes vaporariorum (Westwood) are two of the most widespread and damaging whitefly species. To complete their unbalanced diet, whiteflies harbor the obligatory bacterium Portiera aleyrodidarum. B. tabaci further harbors a diverse array of secondary symbionts, including Hamiltonella, Arsenophonus, Cardinium, Wolbachia, Rickettsia and Fritschea. T. vaporariorum is only known to harbor P. aleyrodidarum and Arsenophonus. We conducted a study to survey the distribution of whitefly species in Croatia, their infection status by secondary symbionts, and the spatial distribution of these symbionts in the developmental stages of the two whitefly species.

Results: T. vaporariorum was found to be the predominant whitefly species across Croatia, while only the Q biotype of B. tabaci was found across the coastal part of the country. Arsenophonus and Hamiltonella were detected in collected T. vaporariorum populations, however, not all populations harbored both symbionts, and both symbionts showed 100\% infection rate in some of the populations. Only the Q biotype of B. tabaci was found in the populations tested and they harbored Hamiltonella, Rickettsia, Wolbachia and Cardinium, while Arsenophonus and Fritschea were not detected in any B. tabaci populations. None of the detected symbionts appeared in all populations tested, and multiple infections were detected in some of the populations. All endosymbionts tested were localized inside the bacteriocyte in both species, but only Rickettsia and Cardinium in B. tabaci showed additional localization outside the bacteriocyte.

Conclusions: Our study revealed unique co-infection patterns by secondary symbionts in B. tabaci and T. vaporariorum. Co-sharing of the bacteriocyte by the primary and different secondary symbionts is maintained through vertical transmission via the egg, and is unique to whiteflies. This system provides opportunities to study interactions among symbionts that co-inhabit the same cell in the same host: these can be cooperative or antagonistic, may affect the symbiotic contents over time, and may also affect the host by competing with the primary symbiont for space and resources.
\end{abstract}

\section{Background}

Whiteflies (Hemiptera: Aleyrodidae) are an extremely important group of agricultural insect pests that cause serious damage by weakening plants, excreting honeydew and transmitting several hundreds of plant viruses [1]. The most economically important of these is the cosmopolitan sweetpotato whitefly Bemisia tabaci (Gennadius), which is a species complex of more than 20 biotypes. The $\mathrm{B}$ and $\mathrm{Q}$ biotypes, among the most predominant and damaging worldwide, differ in many biological parame-

* Correspondence: ghanim@agri.gov.il

2 Department of Entomology, Institute Plant Protection, Agricultural Research Organization, The Volcani Center, Bet Dagan, Israel

Full list of author information is available at the end of the article ters, including resistance to insecticides, ability to damage plants [2] and tolerance to environmental conditions [3]. Another important whitefly insect pest is the greenhouse whitefly Trialeurodes vaporariorum (Westwood) which is less important as a virus vector, but causes serious damage by direct feeding on plants. Whereas T. vaporariorum can be identified based on external morphology (Figure 1), B. tabaci biotypes are only well defined by DNA markers [4].

Symbiosis is quite common among known whitefly species. Both B. tabaci and T. vaporariorum harbor the primary obligatory bacterium Portiera aleyrodidarum, which supplements their unbalanced diet [5]. B. tabaci can also harbor a diverse array of facultative secondary 

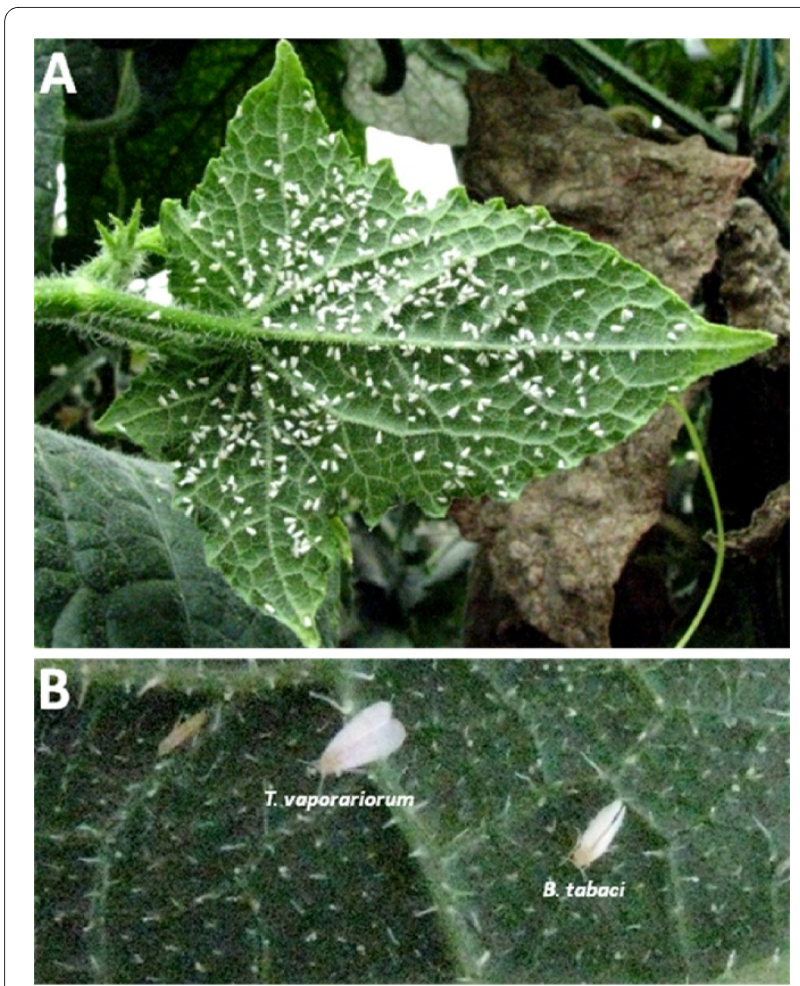

Figure 1 Whiteflies in Croatia. Demonstration of heavy whitefly infestations on cucumbers grown in the coastal part of Croatia (A), and external phenotypical differences between B. tabaci and T. vaporario$\operatorname{rum}(\mathrm{B})$.

symbionts, including the Gammaproteobacteria Arsenophonus (Enterobacteriales), Hamiltonella (Enterobacteriales) [5,6], Fritschea (Chlamydiales) [7] and Cardinium (Bacteroidetes) [8], and the Alphaproteobacteria Rickettsia (Rickettsiales) [9] and Wolbachia (Rickettsiales) [10]. A clear association between B. tabaci biotypes and secondary symbionts has been observed in Israeli populations: Hamiltonella is detected only in the B biotype, Wolbachia and Arsenophonus only in the Q biotype, and Rickettsia in both biotypes [11]. Fritschea has only been detected in the A biotype from the United States [12], and only Arsenophonus has been associated with T. vaporariorum [13]. Virtually nothing is known about the functions these symbionts might fulfill in whiteflies. However, in other arthropods, they may influence their host's nutrition, host plant utilization and ability to cope with environmental stress factors, induce resistance to parasitoids, and effect reproductive manipulations [14]. For example Wolbachia, Cardinium, Rickettsia and Arsenophonus are known to manipulate reproduction in a wide range of insect species by inducing cytoplasmic incompatibilities or sex ratio bias [15-18]. Hamiltonella defensa induces parasitoid resistance in the pea aphid [19], whereas Fritschea bemisiae has no known effect. Recent studies have shown that different single and mixed infections with secondary symbionts in $B$. tabaci can affect the insects' ability to tolerate synthetic pesticides [20,21]. The diversity and infection status of other world whitefly populations have not been documented. In the framework of a large study to identify the status of whitefly pests in Croatia, we describe the distribution of whitefly populations in that country, their infection status by secondary symbionts, co-infections and spatial localization within the insects' developmental stages. Interestingly, infection with secondary symbionts and localization patterns in $B$. tabaci differed in some cases from previously published results. In T. vaporariorum, this is the first time in which such a study has been reported.

\section{Results}

B. tabaci distribution and infection by secondary symbionts Whitefly collections in Croatia were conducted in 20082009. Ten B. tabaci populations (Table 1) were collected only from the coastal part of the country because, surprisingly, B. tabaci was never found inland (the continental part), presumably due to the different climates (Figure 2). Interestingly, testing the collected populations revealed only the $\mathrm{Q}$ biotype. One population collected in the neighboring Monte Negro was identified as B biotype. Twenty individuals from each population were tested for the presence of the different symbionts known from whiteflies using genus-specific primers for each symbiont (Table 2). P. aleyrodidarum, the primary symbiont, was detected in all individuals tested and provided a control for the quality of the extracted DNA. Each box in Figure 3 shows single and mixed infections detected in all of the individuals in a population. For example, the population collected from Turanj on poinsettia plants (population 4 in Table 1) contained only two individuals that were singly infected with Rickettsia, two individuals that harbored only Hamiltonella, one individual that harbored only Wolbachia and three individuals that harbored only Cardinium. This population also contained two individuals that were doubly infected with Rickettsia and Hamiltonella, one individual that was doubly infected with Wolbachia and Cardinium, one individual that was infected with three symbionts--Rickettsia, Wolbachia and Cardinium, and one individual that showed the highest level of mixed infection with four symbionts--Rickettsia, Hamiltonella, Wolbachia and Cardinium. Among the 20 individuals tested from this location, seven did not contain any of the tested secondary symbionts. Fritschea was not detected in this or any other population tested in this study. Although the population from Turanj showed a high level of mixed infection, with one individual harboring four different symbionts, mixed infections with more than one symbiont were not common in many of the tested populations. All populations harbored at least one symbiont or more in some of the individuals tested, and 
Table 1: B. tabaci and T. vaporariorum populations collected across Croatia and neighboring countries in this study

\begin{tabular}{|c|c|c|c|}
\hline Population number & Collection location & Species and biotype & Host plant \\
\hline 1 & Pula & B. tabaci Q & Poinsettia \\
\hline 2 & Zadar & B. tabaci Q & Hibiscus \\
\hline 3 & Turanj & B. tabaci Q & Tomato \\
\hline 4 & Turanj & B. tabaci Q & Poinsettia \\
\hline 5 & Kastela & B. tabaciQ & Hibiscus \\
\hline 6 & Brac & B. tabaci Q & Cucumber \\
\hline 7 & Cavtat & B. tabaci Q & Black nightshade \\
\hline 8 & $\begin{array}{l}\text { Veljaci (Bosnia and } \\
\text { Herzegovina) }\end{array}$ & B. tabaci Q & Zucchini \\
\hline 9 & $\begin{array}{l}\text { Visici (Bosnia and } \\
\text { Herzegovina) }\end{array}$ & B. tabaciQ & Datura \\
\hline 10 & Podgorica (Monte Negro) & B. tabaci B & Hibiscus \\
\hline 11 & Cepin & T. vaporariorum & Gerbera \\
\hline 12 & Velika Ludina & T. vaporariorum & Datura \\
\hline 13 & Zabok & T. vaporariorum & Pumpkin \\
\hline 14 & Donja Lomnica & T. vaporariorum & Strawberries \\
\hline 15 & Karlovac & T. vaporariorum & Zucchini \\
\hline 16 & Novigrad & T. vaporariorum & Tomato \\
\hline 17 & Pula & T. vaporariorum & Petunia \\
\hline 18 & Turanj & T. vaporariorum & Tomato \\
\hline 19 & Split & T. vaporariorum & Tobacco \\
\hline 20 & Tugare & T. vaporariorum & Cucumber \\
\hline 21 & Brac & T. vaporariorum & Cucumber \\
\hline 22 & Metkovic & T. vaporariorum & Tomato \\
\hline 23 & Dubrovnik & T. vaporariorum & Gerbera \\
\hline 24 & $\begin{array}{l}\text { Veljaci (Bosnia and } \\
\text { Herzegovina) }\end{array}$ & T. vaporariorum & Cucumber \\
\hline
\end{tabular}

overall, secondary symbionts were highly prevalent with $82 \%(194 / 236)$ of the individuals having at least one symbiont. Hamiltonella showed the highest prevalence in all populations tested and was detected in $52 \%$ of the individuals tested; sometimes it was the only symbiont detected in a particular population and it was fixed or close to fixation in some populations, for example those collected in Pula, Cavtat and Visici. The presence of each symbiont varied considerably between populations. For example Hamiltonella was fixed in the population from Brac, and this population did not harbor Rickettsia. However, in the population from Zadar, Hamiltonella was found in only one individual while Rickettsia was almost fixed. Single infections were more prevalent (52\% of the total individuals tested) than mixed infections (two or more symbionts in the same individual--31\% of all individuals tested). All symbionts tested were found in at least one or more cases in which they were co-infecting the same individual. Figure 3 demonstrates the high vari- ability in secondary symbiont prevalence in the different populations tested, and while some populations were heterogeneous and contained multiple symbionts (for example the populations from Turanj), other populations were found to be infected with only one symbiont (the populations from Pula and Cavtat).

\section{T. vaporariorum distribution and infection by secondary symbionts}

Fourteen $T$. vaporariorum populations were collected across Croatia's coastal and continental regions as well as from neighboring Bosnia and Herzegovina and tested for the presence of secondary symbionts. T. vaporariorum was much more prevalent than $B$. tabaci in most of the regions, sometimes with heavy infestations in agricultural crops. $P$. aleyrodidarum, the primary symbiont, was detected in all individuals tested. Out of the six secondary symbionts tested in the collected T. vaporariorum populations, only Arsenophonus and Hamiltonella were 
Table 2: List of primers used in this study

\begin{tabular}{|c|c|c|c|c|}
\hline Targeted gene & Primer name & Sequence (5'-> 3') & $\begin{array}{l}\text { Anealing }\left({ }^{\circ} \mathrm{C}\right) / \\
\text { Product Size }\end{array}$ & Reference \\
\hline $\begin{array}{l}\text { Rickettsia } \\
\text { 16S rDNA }\end{array}$ & $\begin{array}{l}\mathrm{Rb}-\mathrm{F} \\
\mathrm{Rb}-\mathrm{R}\end{array}$ & $\begin{array}{l}\text { GCTCAGAACGAACGCTATC } \\
\text { GAAGGAAAGCATCTCTGC }\end{array}$ & 59/ 900 & [9] \\
\hline $\begin{array}{l}\text { Hamiltonella } \\
16 \mathrm{~S} \text { rDNA }\end{array}$ & $\begin{array}{l}92 \mathrm{~F} \\
\mathrm{HbR}\end{array}$ & $\begin{array}{l}\text { TGAGTAAAGTCTGGGAATCTGG } \\
\text { AGTTCAAGACCGCAACCTC }\end{array}$ & $62 / \sim 700$ & {$[10]$} \\
\hline $\begin{array}{l}\text { Cardinium } \\
16 \mathrm{~S} \text { rDNA }\end{array}$ & $\begin{array}{l}\text { CFB-F } \\
\text { CFB-R }\end{array}$ & $\begin{array}{l}\text { GCGGTGTAAAATGAGCGTG } \\
\text { ACCTMTTCTTAACTCAAGCCT }\end{array}$ & $59 / \sim 500$ & {$[8]$} \\
\hline $\begin{array}{l}\text { Arsenophonus } \\
23 \text { S rDNA }\end{array}$ & $\begin{array}{l}\text { Ars23S-1 } \\
\text { Ars23S-2 }\end{array}$ & $\begin{array}{l}\text { CGTTTGATGAATTCATAGTCAAA } \\
\text { GGTCCTCCAGTTAGTGTTACCCAAC }\end{array}$ & $59 / \sim 600$ & [5] \\
\hline $\begin{array}{l}\text { Wolbachia } \\
16 \text { S rDNA }\end{array}$ & $\begin{array}{l}\text { Wol16S-f } \\
\text { Wol16S-r }\end{array}$ & $\begin{array}{l}\text { CGG GGGAAAAATTTATTGCT } \\
\text { AGCTGTAATACAGAAAGTAAA }\end{array}$ & $55 / \sim 650$ & {$[38]$} \\
\hline $\begin{array}{l}\text { Fritschea } \\
16 \mathrm{~S} \text { rDNA }\end{array}$ & $\begin{array}{l}\text { U23F } \\
23 S I G R\end{array}$ & $\begin{array}{l}\text { GATGCCTTGGCATTGATAGGCGATGAAGGA } \\
\text { TGGCTCATCATGCAAAAGGCA }\end{array}$ & $55 / \sim 600$ & [7] \\
\hline $\mathrm{B} / \mathrm{Q}$ biotypes $\mathrm{mtCO} 1$ & $\begin{array}{l}\text { C1-J-2195 } \\
\text { L2-N-3014 }\end{array}$ & $\begin{array}{l}\text { TTGATTITTGGTCATCCAGAAGT } \\
\text { TCCAATGCACTAATCTGCCATATTA }\end{array}$ & $50 / \sim 850$ & {$[57]$} \\
\hline $\begin{array}{l}\mathrm{B} / \mathrm{Q} \text { biotypes micro- } \\
\text { sattelite }\end{array}$ & $\begin{array}{l}\text { Bem23-F } \\
\text { Bem23-R }\end{array}$ & $\begin{array}{l}\text { CGGAGCTTGCGCCTTAGTC } \\
\text { CGGCTTIATCATAGCTCTCGT }\end{array}$ & $\begin{array}{l}55 / Q=400 \\
B=200\end{array}$ & {$[56]$} \\
\hline
\end{tabular}

detected (Figure 4). Arsenophonus was more prevalent than Hamiltonella: it appeared in $71 \%$ of all individuals tested (107/150), as a single infection in $37 \%$ of all individuals, while the latter was detected in $40 \%$ of all individuals, and appeared as a single infection in $6 \%$ of all individuals (Figure 4). The prevalence of Arsenophonus was always higher or equal to that of Hamiltonella in all populations tested except for the population from the island Brac. Two of the populations tested were not infected with Hamiltonella (Pula and Turanj) and one population showed fixation of both symbionts (Metkovic); $34 \%$ (51/150) of all individuals tested were doubly infected with Arsenophonus and Hamiltonella (Figure 4).

Localization of secondary symbionts in B. tabaci and T. vaporariorum

None of the controls used with the samples submitted to fluorescence in situ hybridization (FISH) showed any signal (data not shown). All tested symbionts varied in their localization pattern, which could be divided into two types: total confinement to the bacteriocyte during all developmental stages, and confinement combined with scattered localization outside the bacteriosome during some of the developmental stages.
Hamiltonella was localized to small areas inside the bacteriocyte: these areas appeared sometimes as independent and homogenous small patches as in T. vaporariorum (Figure 5A-C) and sometimes continuous and irregular as in B. tabaci (Figure 6). These patterns of localization were observed in eggs, nymphs and adults of both T. vaporariorum and B. tabaci (Figs. 5A-C and 6). The pattern of localization of Arsenophonus in T. vaporariorum was similar to that of Hamiltonella (Figure 5DF). Both symbionts always co-localized with Portiera which occupied most of the bacteriocyte. The continuous and irregular localization phenotype of Hamiltonella has been previously observed in B. tabaci by FISH and TEM [22]; however the phenotype in T. vaporariorum is different. Hamiltonella and Arsenophonus were never observed outside the bacteriocyte. Sequencing of $900 \mathrm{bp}$ of the 16S rRNA Hamiltonella gene from T. vaporariorum showed 95\% similarity with B. tabaci Hamiltonella (data not shown). Interestingly, Arsenophonus always colocalized to exactly the same areas with Hamiltonella, in eggs, nymphs and adults of T. vaporariorum (Figure 7). Previously described $B$. tabaci Q biotype populations have never been reported to harbor Hamiltonella; how- 


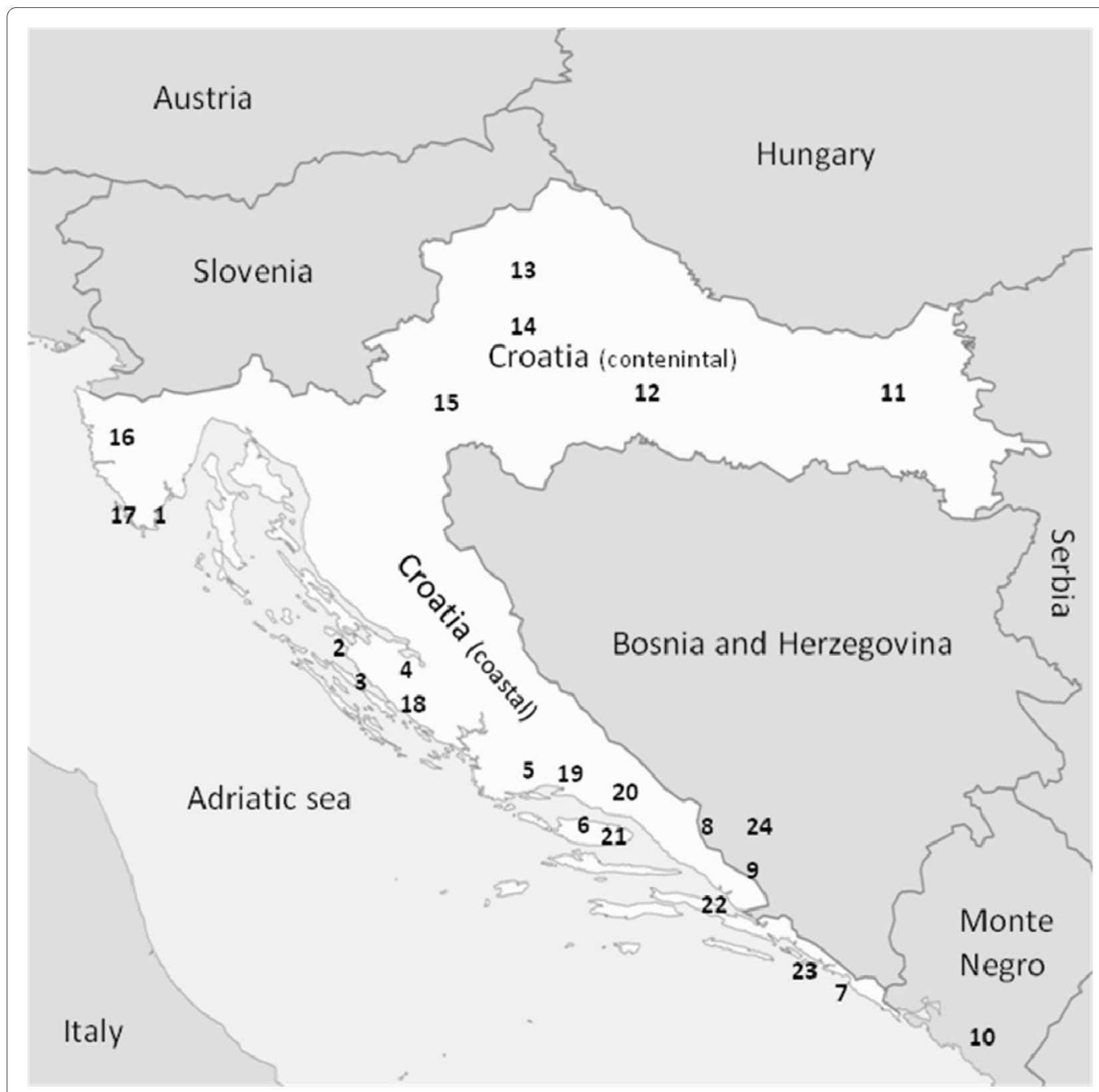

Figure 2 Distribution of whiteflies in Croatia. Locations of the populations collected in this study in Croatia and neighboring countries. Names of locations are given in Table 1.

ever, those populations were infected with Arsenophonus at high rates, and thus the two symbionts could not be observed in the same individual. Conversely, Arsenophonus was not observed in any of the B. tabaci populations collected in this study, which did harbor Hamiltonella. Thus these two endosymbionts never co-localized in the same B. tabaci individual, whereas they co-localized in $T$. vaporariorum. The localization pattern of Arsenophonus in T. vaporariorum also resembled that of its previously published localization in B. tabaci [22], and it was observed to be rod-shaped, in agreement with TEM and light microscopic images of cell lines infected with this bacterium [23].

Cardinium showed a dual localization pattern, outside and inside the bacteriocyte, with Portiera in the same $B$. tabaci individuals (Figure 8). Cardinium, like all symbionts that are confined to the bacteriocyte, is transovarially transferred from the mother to the offspring though the egg. Thus in the egg's early developmental stages, it is confined to the bacteriocyte; however, in older eggs (5-7 days), it is also observed outside the bacteriocyte (not shown), and in later nymphal and adult stages, it occupies 


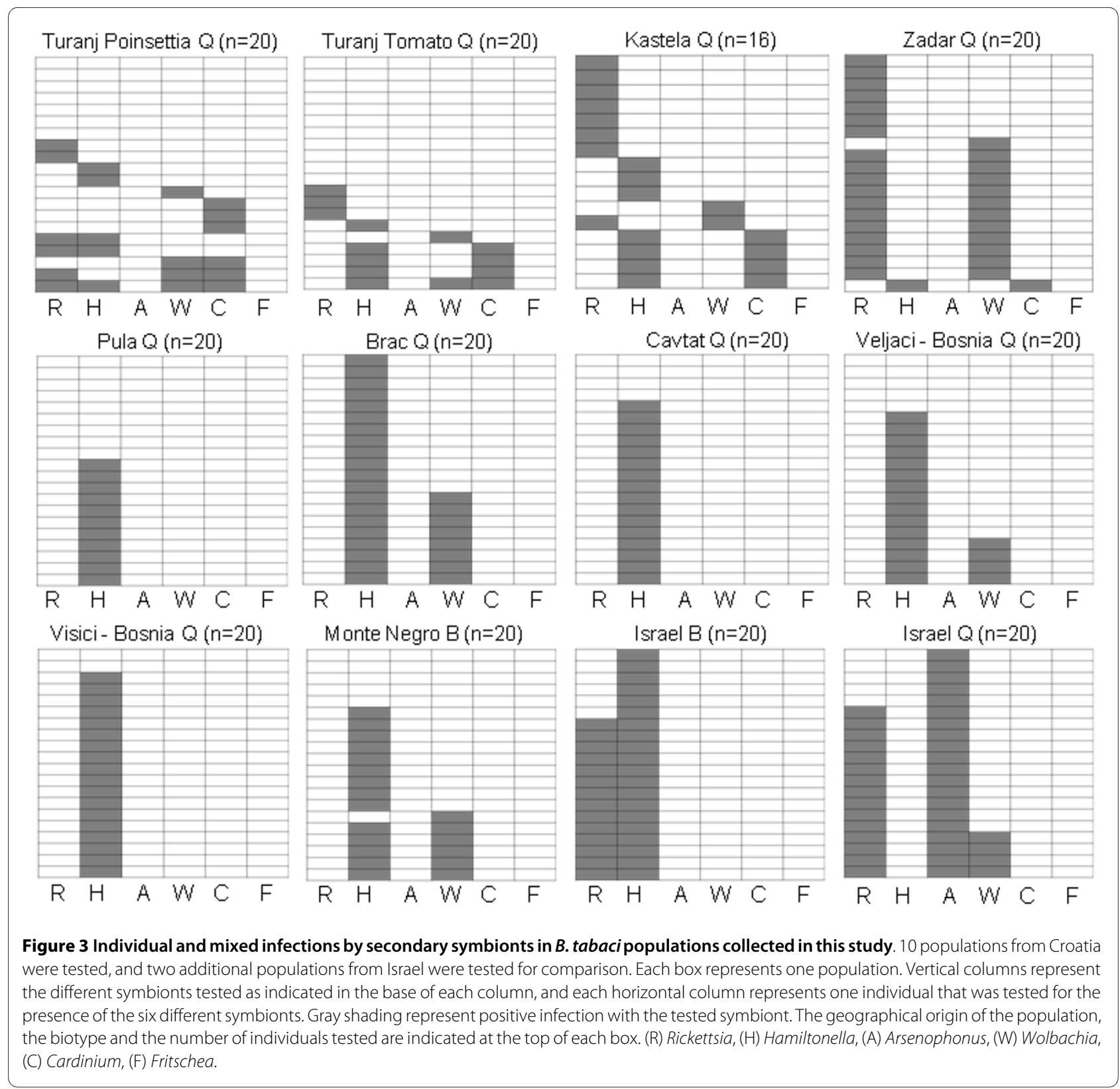

most of the body tissues, including the bacteriocyte (Figure 8). Cardinium was not detected in T. vaporariorum. Cardinium has been shown by TEM to localize to the bacteriocytes of the A and Jatropha biotypes of $B$. tabaci [24]. Our PCR screening assay revealed co-localization of Cardinium in B. tabaci populations (in 15 out of a total 236 individuals tested), mostly with Hamiltonella (10 of the 15 Cardinium-containing individuals also harbored Hamiltonella--66\% co-localization). In some cases, multiple infections of Cardinium with two (Wolbachia and Rickettsia) or three (Rickettsia, Wolbachia and Hamiltonella) symbionts were observed. The localization pattern of Cardinium as seen by FISH was different from that of the other symbionts that co-localized with it. Localiza- tion of Hamiltonella and Cardinium has also been demonstrated in the bacteriocytes of the A biotype together with Portiera, as shown here. TEM has revealed the presence of Cardinium in the spermatid cytoplasm, residual bodies, and cyst cell cytoplasm of B. tabaci males [25]. Studies on other hosts have reported the presence of Cardinium in a diverse array of tissues, including the reproductive tract [26], fat bodies, and salivary glands [27,28], as well as inside bacteriocytes surrounded by oogonia in the apical region of the ovary [29].

Wolbachia has been previously shown to localize at the circumference of and inside the bacteriocytes. In adults, Wolbachia can also be seen in the abdomen outside the bacteriocyte [22]. Surprisingly, in our FISH analysis, Wol- 


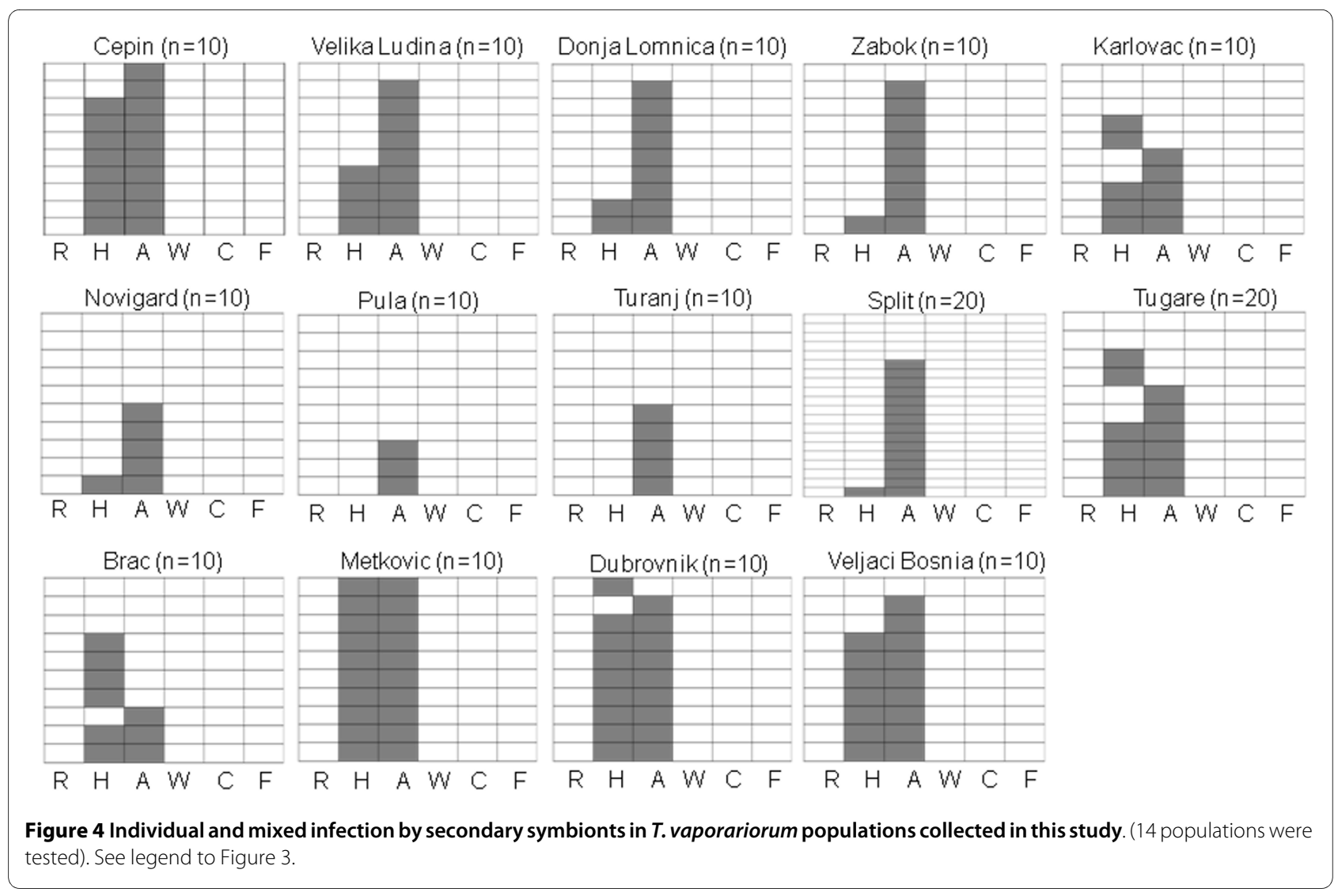

bachia could only be detected inside the bacteriocytes with the primary symbiont, and signal was not detected in any other organ at any developmental stage (Figure 9 shows the results from nymphs). The localization signal was evenly distributed in the bacteriocyte cells, but it was stronger at the cell's circumference. This different localization pattern suggests the presence of a different strain of Wolbachia in Croatian B. tabaci populations. In other insects, Wolbachia has been localized to organs other than the bacteriocytes, including the salivary glands, gut, Malpighian tubules, fat body and brain [30-32]. Wolbachia has been shown to influence the reproduction of its host and to localize to ovarian cells and developing embryos [33-35]. The localization pattern here suggests different functions for Wolbachia in B. tabaci. In our PCR screens, Wolbachia co-localized with one or more of the symbionts--with Cardinium alone, with Cardinium and Rickettsia in some individuals, with Cardinium and Hamiltonella or with Hamiltonella, Cardinium and Rickettsia. It could also be detected as a single infection. In other insects, Wolbachia has been found localized with other bacteria: in the aphid Cinara cedri, it has been found in the bacteriocytes together with Serratia symbiotica, and in the weevil Sitophilus oryzae, it co-exists with the primary symbiont $[36,37]$.
Rickettisa is vertically transferred with the primary symbiont into the newly developing egg. Once the new bacteriocyte cell enters the mature developing egg, it moves towards the center of the egg, and Rickettsia leaves it and occupies most of the egg cavity (Figure 10) $[9,38]$. At later stages (nymphs and adults), it is found throughout the body, except in the bacteriocytes. In the confined phenotype, Rickettsia is always associated with the bacteriocyte and never observed outside it. In this study, we never observed the confined phenotype, and Rickettsia distribution in the eggs was similar to previously published results [9]. However, in the nymphal stage, Rickettsia appeared to be localized inside and outside the bacteriocytes (Figure 10C). In this phenotype, Rickettsia cells were mostly concentrated at the circumference of the bacteriocyte cells with some sort of adhesion. Furthermore, in adults, a much higher concentration of Rickettsia-associated signal was consistently observed near and around the bacteriocytes relative to the rest of the body. Rickettsia could also be observed in the head, thorax and abdomen.

\section{Discussion}

This study presents a comprehensive survey of the two most widespread whitefly species in Croatia, $T$. vaporari- 

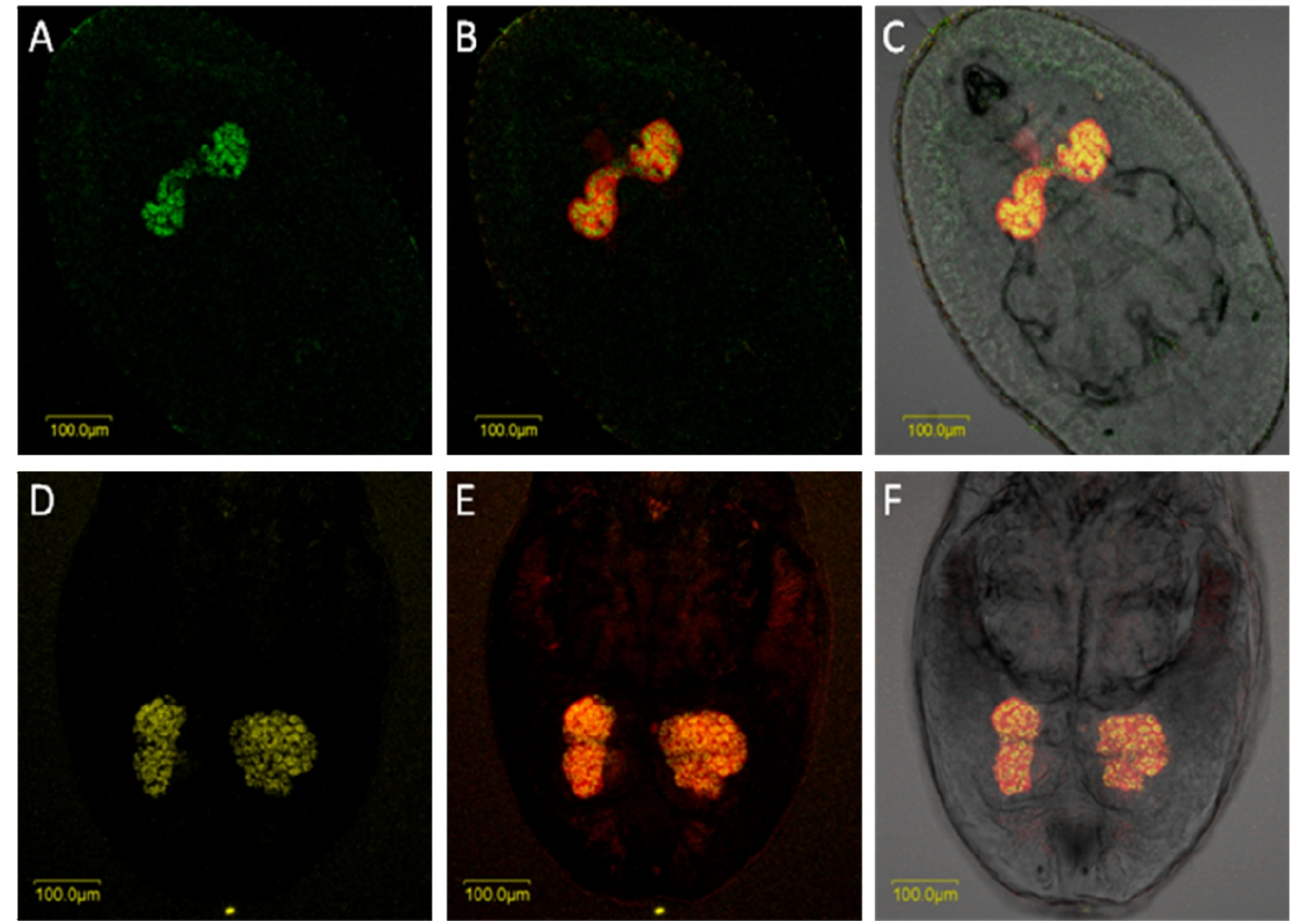

Figure 5 Portiera, Arsenophonus and Hamiltonella FISH of T. vaporariorum nymphs. Portiera-specific probe (red) and probes specific to secondary symbionts Hamiltonella (green) and Arsenophonus (yellow) were used. A-C: FISH of Hamiltonella alone (A), double FISH of Hamiltonella and Portiera under dark field (B), and double FISH of Hamiltonella and Portiera under bright field (C). D-F: FISH of Arsenophonus alone (D), double FISH of Arsenophonus and Portiera under dark field (E), and double FISH of Arsenophonus and Portiera under bright field (F).

orum and B. tabaci, and their infection status by secondary symbionts. Their geographical distribution (Figure 2) was such that B. tabaci was not found in the continental part of the country. This is most likely due to climate differences between the coastal and continental parts. $T$. vaporariorum, however, was collected from all parts of the country. B. tabaci was found to harbor Rickettsia, Wolbachia, Cardinium and Hamiltonella, whereas $T$. vaporariorum harbored only Arsenophonus and Hamiltonella. Thus Hamiltonella was the only endosymbiont common to both whitefly species. Sequences of the $16 \mathrm{~S}$ rRNA gene of Hamiltonella from the different $B$. tabaci populations tested in this study were identical as was the case with sequences of the same gene from all T. vaporariorum populations. Comparing the sequences of the $16 \mathrm{~S}$ rRNA gene from Hamiltonella of both whitefly species revealed 95\% similarity. This high similarity suggests different strains of Hamiltonella that colonize both whitefly species, however, ancient occurrence of horizontal transfer between the two species, after which Hamiltonella became localized to the bacteriocyte, cannot be excluded. These two whitefly species feed through the plant phloem and share host plants (Figure 1), and horizontal transmission can therefore occur through the host $[33,39]$. Furthermore, whiteflies share host plants with other phloem-feeders such as aphids, planthoppers and leafhoppers, which are also known to harbor endosymbionts $[33,39,40]$. These insects can inject endosymbionts into the vascular system which then follow the circulative pathway of transmission, reaching the salivary glands of the insect which might be involved in transmitting these symbionts [41]. A recent study has shown that salivary glands can indeed be infected by endosymbionts, as in the case of Cardinium in Scaphoideus titanus [26,42].

It is difficult to hypothesize how infections with symbionts occurred among whiteflies on an evolutionary scale: it might have been the result of horizontal transmission, loss or new acquisition of symbionts, which would partially explain the mixed infections and heterogeneity among some of the collected populations. Some popula- 

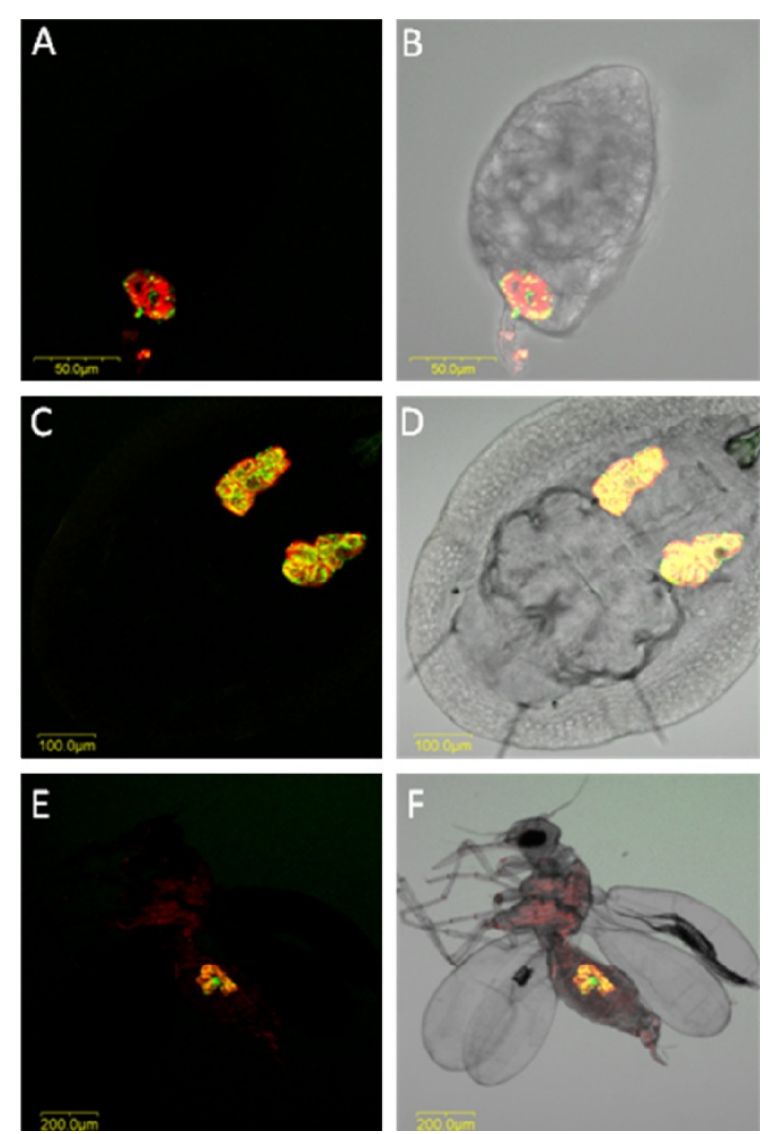

Figure 6 Portiera and Hamiltonella FISH of B. tabaci eggs, nymphs and adults. Portiera-specific probe (red) and Hamiltonella-specific probe (green) were used. A, C and E: double FISH of Portiera and Hamiltonella in eggs (A), nymphs (C) and adults (E) under dark field. B, D and F: double FISH of Portiera and Hamiltonella in eggs (B), nymphs (D) and adults (F) under bright field.

tions showed very low infection rates or lacked some of the symbionts, suggesting the recent introduction of those symbionts into the populations, possibly through horizontal transfer or introduction of new whitefly populations with new symbiotic complements into Croatia via regular trade of plants. For example, among the 20 individuals tested in the Zadar population, only one individual showed infection with Hamiltonella and Cardinium. The multiple infections observed among some of the populations, such as those from Turanj and Kastela, can also be explained by efficient horizontal transfers, which allowed the appearance of maximum symbionts in one population. However, some other internal factors may influence maximum horizontal transfers and maximum infection rates in the same individuals. These factors include competition for space and resources among two or more symbionts $[22,43]$, or on the contrary, positive interaction between the symbionts may contribute to maximum infection in one individual [44]. Another important factor is the host response to the presence of these symbionts which in most cases will influence the bacterial community residing within the host.

The occurrence of mixed infections in both species also suggests that these secondary symbionts are non-essential for these whiteflies, allowing their presence to be variable. In one report, Hamiltonella was found in $40 \%$ of $B$. tabaci populations [45], and 0 to $40 \%$ of pea aphid populations have been found to harbor Rickettsia [45-50]. Only Hamiltonella was highly prevalent in B. tabaci populations and sometimes reached fixation, an indication of a mutualistic or obligatory interaction with the insect. Such interactions can occur via complementation of the primary symbiont's function with regard to completing the host's dietary needs or enhancing host fitness.

All of the symbionts detected in both whitefly species were located together with the primary symbiont Portiera in the bacteriocytes at one or more stages of development. However, some were strictly localized to the bacteriocytes during all developmental stages--Hamiltonella and Wolbachia in B. tabaci, and Hamiltonella and Arsenophonus in T. vaporariorum, while others were located inside and outside the bacteriocyte--Rickettsia and Cardinium in B. tabaci. Symbionts that are strictly localized to the bacteriocytes are vertically transmitted and thus they may contribute to their host's fitness [51]. However, they are less likely to be able to manipulate their host's reproduction since this requires invading reproductive organs outside the bacteriocyte. Thus, the restricted localization of Hamiltonella in both B. tabaci and T. vaporariorum, Wolbachia in B. tabaci and Arsenophonus in $T$. vaporariorum suggests their involvement in providing the host with a functional advantage rather than in manipulating its reproduction. Interestingly, Wolbachia was localized to the bacteriocyte and was not observed outside it, invading other organs. Wolbachia can be found in all major insect orders at various different frequencies, and it has been associated with reproductive disorders [16]. However, the localization pattern in B. tabaci observed here suggests that Wolbachia does not manipulate reproduction in this whitefly, but rather performs other unknown functions. It cannot be excluded that at some stages of the adult development, Wolbachia may invade the reproductive system and causes known reproductive manipulations, however, discovering this requires more investigations. One major advantage of the confined localization of some symbionts with the primary symbiont in the bacteriocyte is that the host immune system is thus avoided, representing a bidirectional advantage for the host which invests fewer resources in maintaining the symbiont levels and for the symbiont, which is not recognized by the immune system of the host. This confined localization ensures low cell numbers 

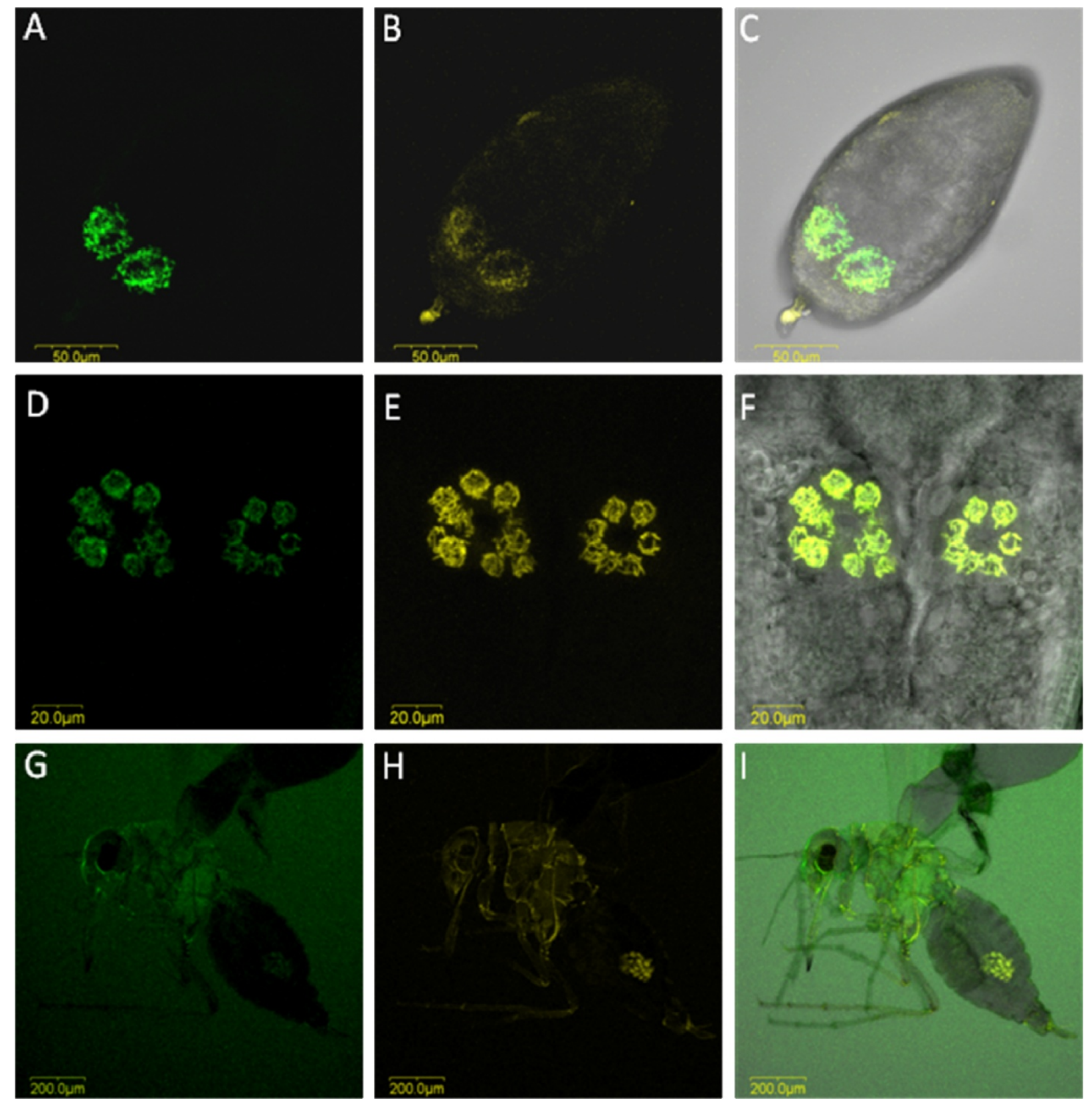

Figure 7 Hamiltonella and Arsenophonus FISH of $T$. vaporariorum eggs, nymphs and adults. Secondary symbiont-specific probes for Hamiltonella (green) and Arsenophonus (yellow) were used. A, D and G: FISH of Hamiltonella alone in eggs (A), nymphs (D) and adults (G). B, E and H: FISH of Arsenophonus alone in eggs (B), nymphs (E) and adults (H). C, F and I: double FISH of Hamiltonella and Arsenophonus in eggs (C), nymphs (F) and adults (I).

of the bacterium because of the limited space in the bacteriosome, and thus for the host, a lower fitness cost is associated with maintaining the symbiont. An additional advantage for the symbiont is the ease of vertical transmission from one generation to the next. "Hitching a ride" with the primary symbiont in the bacteriocyte exempts the secondary symbiont from invading and entering the egg alone during oogenesis, and ensures its transmission during the transfer of the bacteriocyte to the egg [16].

The localization pattern of the secondary symbionts confined to the bacteriocyte in both B. tabaci and T. vaporariorum showed some specific localization to patches. This localization pattern was consistent in all of the individuals tested, and suggests specific sharing inside the bacteriocyte, with each symbiont, primary and second- 

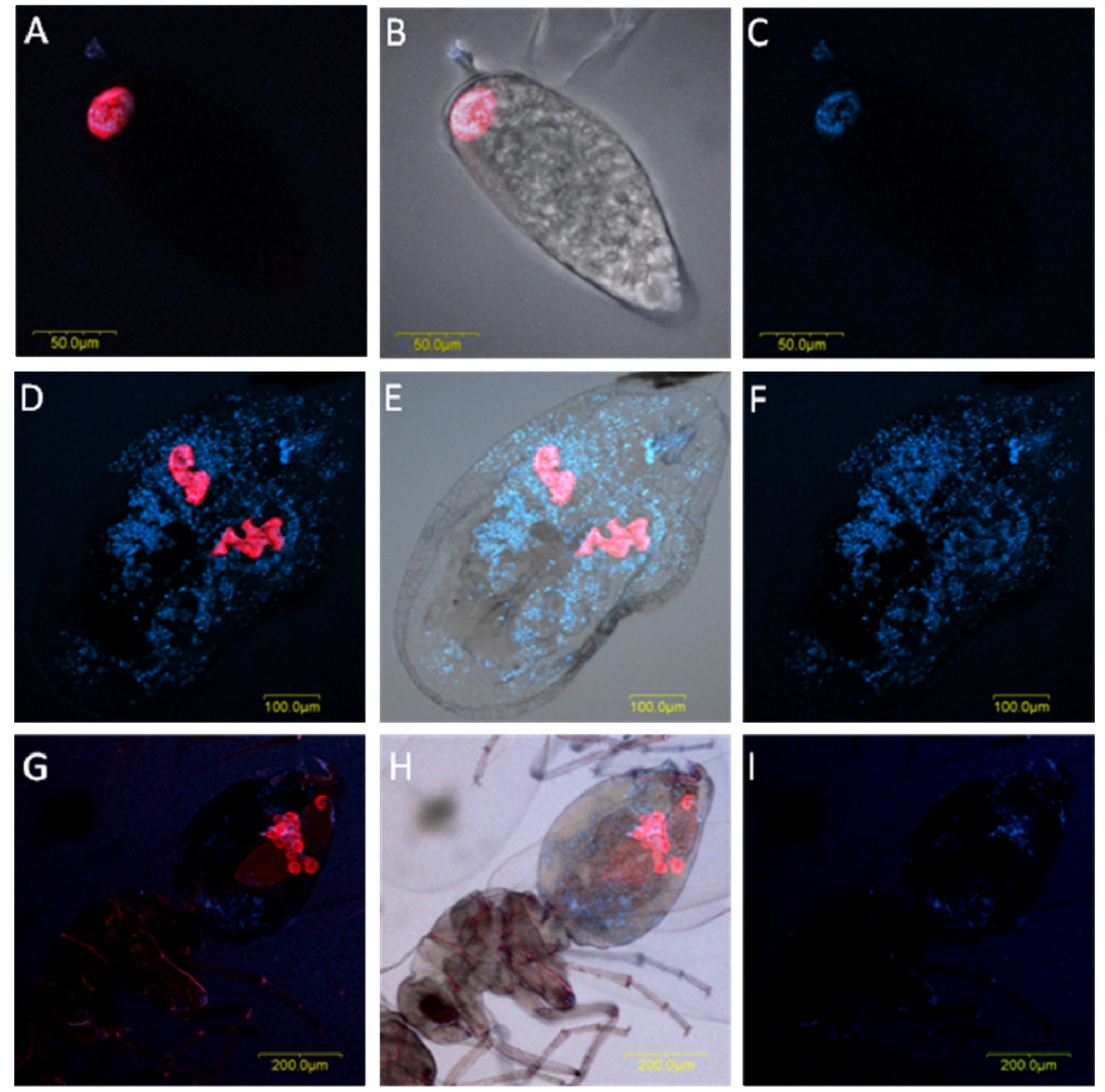

Figure 8 Portiera and Cardinium FISH of B. tabaci eggs, nymphs and adults. Portiera-specific probe (red) and Cardinium-specific probe (blue) were used. A, C and G: double FISH of Portiera and Cardinium in eggs (A), nymphs (D) and adults (G) under dark field. B, E and H: double FISH of Portiera and Cardinium in eggs (B), nymphs (E) and adults (H) under bright field. C, F and I are shown only with Cardinium probe to emphasize its location inside the bacteriosome.

ary, occupying its own niche. Interestingly, all of the symbionts detected in B. tabaci were found to co-exist in the same individual, in varying percentages, suggesting little or no competition for space, with the exception of Arsenophonus and Hamiltonella which were not found together in $B$. tabaci, although they were found together in $T$. vaporariorum. Interestingly, in this latter species, their localization pattern in the bacteriocyte looked exactly the same, suggesting localization in exactly the same places or one inside the other [52]. Future experiments using TEM and ultrastructural localization should shed more light on the exact location of these symbionts relative to one another.

In contrast to the symbionts that were restricted to the bacteriocytes, Rickettsia and Cardinium in B. tabaci showed a scattered localization pattern and were seen outside the bacteriocyte. These two symbionts are known to manipulate host reproduction in many arthropods 

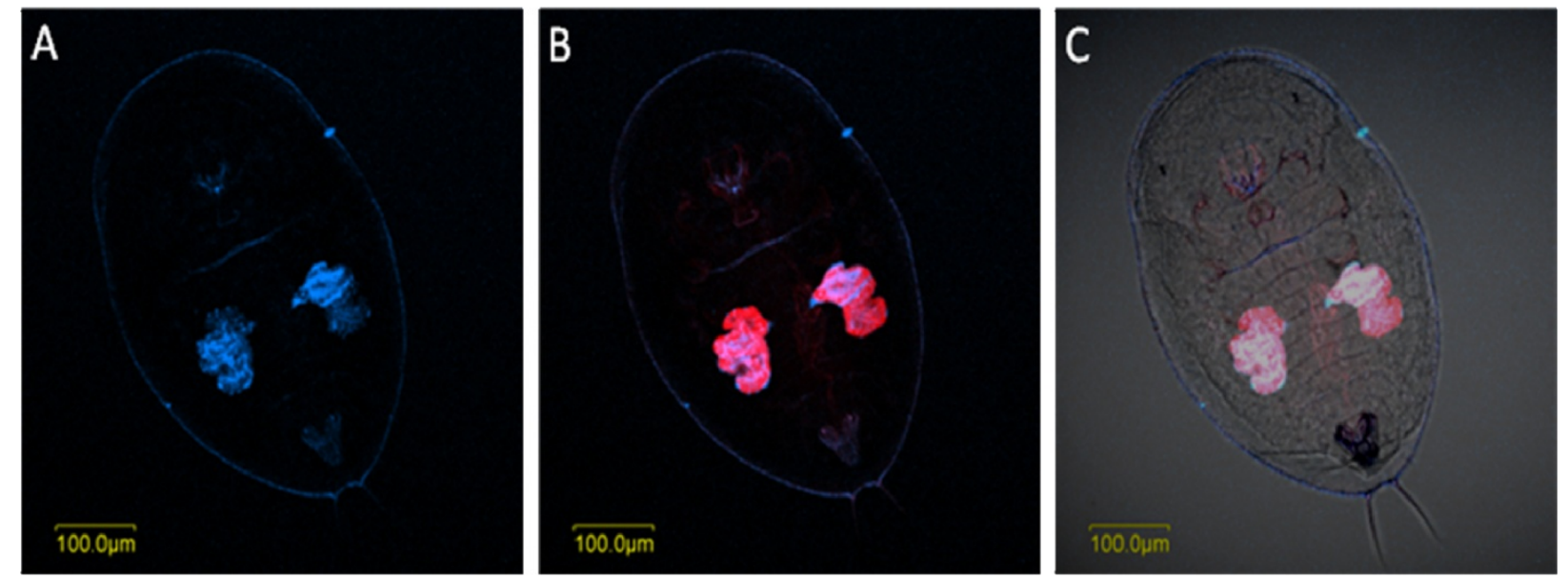

Figure 9 Portiera and Wolbachia FISH of B. tabaci nymphs. Portiera-specific probe (red) and Wolbachia-specific probe (blue) were used. A: single FISH of Wolbachia under dark field, B: double FISH of Wolbachia and Portiera under dark field, C: double FISH of Wolbachia and Portiera under bright field.
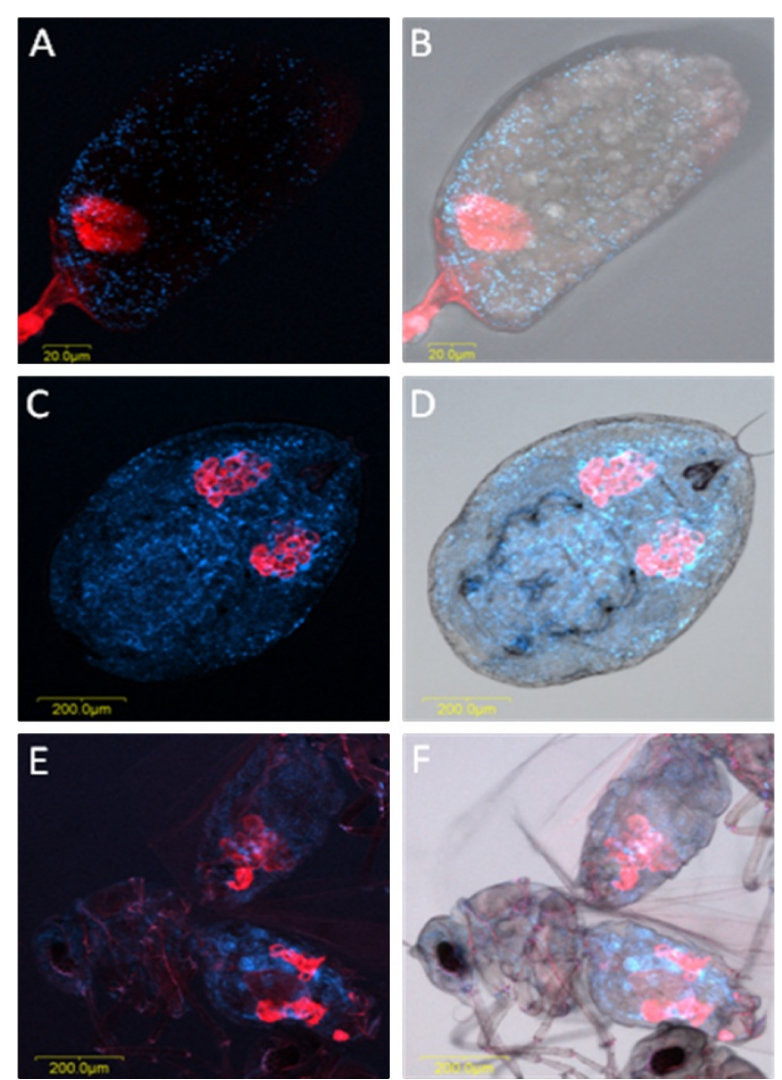

Figure 10 Portiera and Rickettsia FISH of B. tabaci eggs, nymphs and adults. Portiera-specific probe (red) and Rickettsia-wspecific probe (blue) were used. A, C and E: double FISH of Portiera and Rickettsia in eggs (A), nymphs (C) and adults (E) under dark field. B, D and F: double FISH of Portiera and Rickettsia in eggs (B), nymphs (D) and adults (F) under bright field.
$[53,54]$, and this fits well with their localization pattern in B. tabaci. Previously, Rickettsia has been shown to exhibit two different localization phenotypes: scattered throughout the body and confined to the bacteriocyte [22]. These two phenotypes were never observed together in the same individuals. It is not clear whether these localization phenotypes are characteristic of the host or if they are due to different bacteria localizing differently in the host's body. Our FISH results showed the presence of both scattered and confined phenotypes in the same individuals for Rickettsia (Figure 10), and Cardinium (Figure 8). These phenotypes are similar to the obligatory Rickettsia in booklice, in which it was found to appear with both phenotypes in the same individual [55]. We further observed concentration of Rickettsia at the circumference of the bacteriocyte, suggesting a stage in which Rickettsia concentrates around the developing oocytes for entry, for transferral to the next generation.

\section{Conclusions}

Our study describes the distribution of two whitefly species in Croatia and their infection and co-infection status by secondary symbionts. Co-infections revealed a unique pattern of co-sharing the bacteriocyte by the primary and different secondary symbionts. Co-sharing of the same cell by multiple symbionts while maintaining infections over time by vertical transmission through the egg is unique in whiteflies. This sharing provides a unique system to study interactions among bacteria that co-inhabit the same cell. Positive and/or negative interactions among these symbionts--cooperation and antagonism-are part of the multiple interactions that one can expect within their small niche. Competition between symbionts 
Table 3: List of probes used for FISH in this study

\begin{tabular}{llll}
\hline Target symbiont & Probe name and dye & Sequence (5'-> 3') & Reference \\
\hline Portiera & BTP1-Cy3 & TGTCAGTGTCAGCCCAGAAG & {$[9]$} \\
Rickettsia & Rb1-Cy5 & TCCACGTCGCCGTCTTGC & {$[9]$} \\
Hamiltonella & BTH-Cy5/Cy3 & CCAGATTCCCAGACTTACTCA & {$[22]$} \\
Cardinium & Card-Cy5 & TATCAATTGCAGTTCTAGCG & {$[58]$} \\
Arsenophonus & Ars2-Cy5 & TCATGACCACAACCTCCAAA & {$[22]$} \\
Wolbachia & W1-Cy5 & CTTCTGTGAGTACCGTCATTATC & {$[33]$} \\
\hline
\end{tabular}

for space and resources may affect their small environment and their host. The host can be affected through competition between the primary and secondary symbionts within the bacteriocyte. Such microbial diversity provides a unique opportunity for artificial interference and manipulation to disrupt this diverse community as a better means of controlling whiteflies, which are major pests in many agricultural systems.

\section{Methods}

\section{Whitefly collections}

Populations of the sweet potato whitefly B. tabaci and the greenhouse whitefly $T$. vaporariorum were collected during the years 2008-2009 across Croatia. Attempts were made to include populations from all parts of the country, but in some areas, no whiteflies could be found. In addition, three populations were collected from Bosnia and Herzegovina, and one population from Monte Negro for comparison with nearby countries. The whiteflies were collected from the plants into glass Pasteur pipettes attached to a mechanical hand-held aspirator. Each collected population in each location was collected from different leafs on different plants. Some of the populations were collected in greenhouses, and some in open fields and private gardens. Table 1 shows a list of the collected whitefly populations from the different locations and the host plants on which these populations were collected. After collection, all adult individuals were immediately transferred to absolute ethanol for preservation and were kept at room temperature until processing for secondarysymbiont screening.

\section{Whitefly population rearing}

After collection from the field, three whitefly populations (Zadar, Kastela, Turanj) were directly transferred as adults to insect-proof cages containing cotton cv. Acala seedlings (obtained from Zeraim Gedera, Israel). These adults were given a week to lay eggs and to establish a colony. The colonies were then maintained in the laboratory under standard conditions $\left(26 \pm 2^{\circ} \mathrm{C}, 60 \% \mathrm{RH}, 14 / 10 \mathrm{~h}\right.$ of light/dark).

\section{Identification of B. tabaci biotypes}

Biotypes were identified using microsatellite markers with the primer pair Bem23 which distinguishes between $\mathrm{B}$ and $\mathrm{Q}$ biotypes based on the fragment size amplified [56]. Another method was used to verify the B and Q biotypes which consisted of sequencing a fragment of the mitochondrial (mt) COI gene after amplification by PCR. The PCR conditions for amplifying mtCOI and the microsatellite markers were as previously described [11], and the primer sequences are given in Table 2.

\section{Screening for the presence of secondary symbionts}

Whiteflies $(n=10-20)$ were individually analyzed for the presence of secondary symbionts and for biotype determination. Genomic DNA from each whitefly was isolated in lysis buffer as previously described $[11,57]$. The same DNA from each individual was used to screen for the presence of all potential symbionts and for biotype. The presence of Hamiltonella, Rickettsia, Wolbachia, Arsenophonus, Cardinium and Fritschea in the samples was determined using genus-specific primers for amplifying $16 \mathrm{~S}$ or $23 \mathrm{~S}$ rDNA gene fragments (Table 2). PCRs were carried out as previously described [11]. PCR products were visualized on $1.5 \%$ agarose gel containing ethidium bromide. To verify the identity of the PCR products, bands were excised from the gel and DNA was isolated from them and sent for sequencing (ABI 3700 DNA analyzer, Hylabs, Rehovot, Israel). The resulting sequences were run against the non-redundant nucleotide database using the BLAST algorithm of the National Center for Biotechnology Information (NCBI).

\section{Fluorescent in situ hybridization analysis}

FISH analysis of adults, nymphs and eggs was performed as previously described [22] using short symbiont-specific 16S/23S rRNA DNA probes harboring a fluorescent Cy3/Cy 5 molecule on their 5 ' end (Table 3). Absence of cross hybridizations and probe specificity was tested using the "probe match" analysis tool in the Ribosomal Database Project II http://rdp.cme.msu.edu/. Stained samples were mounted whole and viewed under an IX81 Olympus FluoView 500 confocal microscope (Olympus, 
Tokyo, Japan). For each developmental stage, at least 50 specimens were viewed under the microscope to confirm reproducibility. Optical sections(0.7-1.0 $\mu$ m thick) were prepared from each specimen. Specificity of detection was confirmed using no probe staining and RNasedigested specimen staining. In addition, each population was tested with all of the probes listed in Table 2 as controls. Thus, staining of a population known not to have a particular symbiont but harboring others was performed.

\section{Authors' contributions}

MS performed the experiments. SK participated in rearing the whitefly populations and performing some of the experiments. MS, KZ, SGB and MG collected whitefly populations in Croatia. MG and MS designed the study. MG drafted the manuscript. All authors have read and approved the final manuscript.

\section{Acknowledgements}

MS was supported by a travel fellowship to Israel by The National Foundation for Science, Higher Education and Technological Development of the Republic of Croatia - NZZ (Fellowship for doctoral students). Part of this research was supported by grant number 884/07 from the Israel Science Foundation to MG, and by grant number 091-0910468-0281 from the Ministry of Science, Education and Sports, Republic of Croatia to SGB.

\section{Author Details}

'Department of Applied Sciences (Plant Protection), Institute for Adriatic Crops, Split, Croatia and 2Department of Entomology, Institute Plant Protection, Agricultural Research Organization, The Volcani Center, Bet Dagan, Israel

Received: 13 December 2009 Accepted: 12 May 2010

Published: 12 May 2010

\section{References}

1. Brown JK, Czosnek H: Whitefly transmitted viruses. In Advances in Botanical Research Edited by: Plumb RT. New York, Academic Press; 2002:65-100.

2. Shuster DJ, Kring JB, Price JF: Relationship of the sweetpotato whitefly to a new tomato fruit disorder in Florida. Hortscience 1991, 25:1618-1620.

3. Mahadav A, Kontsedalov S, Czosnek H, Ghanim M: Thermotolerance and gene expression following heat stress in the whitefly Bemisia tabaci $\mathrm{B}$ and Q biotypes. Insect Biochem Mol Biol 2009, 39:668-676.

4. Boykin LM, Shatters RG Jr, Rosell RC, McKenzie CL, Bagnall RA, De Barro PJ, Frohlich DR: Global relationships of Bemisia tabaci (Hemiptera: Aleyrodidae) revealed using Bayesian analysis of mitochondrial $\mathrm{COI}$ DNA sequences. Mol Phylogenet Evol 2007, 3:1306-1319.

5. Thao ML, Baumann P: Evolutionary relationships of primary prokaryotic endosymbionts of whiteflies and their hosts. App/ Environ Microbiol 2004, 70:3401-3406.

6. Moran NA, Degnan PH, Santos SR, Dunbar HE, Ochman H: The players in a mutualistic symbiosis: insects, bacteria, viruses, and virulence genes. Proc Natl Acad Sci USA 2005, 102:16919-16926.

7. Everett KDE, Thao ML, Horn M, Dyszynski GE, Baumann P: Novel chlamydiae in whiteflies and scale insects: endosymbionts 'Candidatus Fritschea bemisiae' strain Falk and 'Candidatus Fritschea eriococci' strain Elm. Int J Sys Evol Microbiol 2005, 55:1581-1587.

8. Weeks AR, Breeuwer JAJ: A new bacterium from the CytophagaFlavobacterium-Bacteroides phylum that causes sex ratio distortion. In Insect Symbiosis // Edited by: Bourtzisn K, Miller T. Florida: CRC Press; 2003:165-176.

9. Gottlieb Y, Ghanim M, Chiel E, Gerling D, Portnoy V, Steinberg S, Tzuri G, Horowitz AR, Belausov E, Mozes-Daube N, Kontsedalov S, Gershon M, Gal S, Katzir N, Zchori-Fein E: Identification and localization of a Rickettsia sp. in Bemisia tabaci (Homoptera: Aleyrodidae). Appl Environ Microbiol 2006, 72:3646-3652

10. Zchori-Fein E, Brown JK: Diversity of prokaryotes associated with Bemisia tabaci (Gennadius) (Hemiptera: Aleyrodidae). Ann Entomol Soc Am 2002, 95:711-718.
11. Chiel E, Gottlieb Y, Zchori-Fein E, Mozes-Daube N, Katzir N, Inbar M, Ghanim M: Biotype-dependent secondary symbiont communities in sympatric populations of Bemisia tabaci. Bull Entomol Res 2007, 97:407-413.

12. Thao ML, Baumann L, Hess JM, Falk BW, Ng JC, Gullan PJ, Baumann P. Phylogenetic evidence for two new insect-associated Chlamydia of the family Simkaniaceae. Curr Microbiol 2003, 47:46-50.

13. Thao ML, Baumann L: Evidence for multiple acquisition of Arsenophonus by whitefly species (Sternorrhyncha: Aleyrodidae). Curr Microbiol 2004, 48:140-144

14. Haine ER: Symbiont-mediated protection. Proc Bio/ Sci 2008 275:353-361.

15. Balas MT, Lee MH, Werren JH: Distribution and fitness effects of the sonkiller bacterium in nasonia. Evol Ecol 1996, 10:593-607.

16. Stouthamer R, Breeuwer JAJ, Hurst GDD: Wolbachia pipientis: Microbial manipulator of Arthropod reproduction. Annu Rev Microbiol 1999, 53:71-102.

17. Lawson ET, Mousseau TA, Klaper R, Hunter MD, Werren JH: Rickettsia associated with male-killing in a buprestid beetle. Heredity 2001, 86:497-505

18. Hunter MS, Perlman SJ, Kelly SE: A bacterial symbiont in the Bacteroidetes induces cytoplasmic incompatibility in the parasitoid wasp Encarsia pergandiella. Proc Royal Soc London B 2003, 270:2185-2190.

19. Oliver KM, Russell JA, Moran AN, Hunter MS: Facultative bacterial symbionts in aphids confer resistance to parasitic wasps. Proc Natl Acad SciUSA 2002, 100:1803-1807.

20. Ghanim M, Kontsedalov S: Susceptibility to insecticides in the Q biotype of Bemisia tabaci is correlated with bacterial symbiont densities. Pest Manag Sci 2009, 65:939-942

21. Kontsedalov S, Zchori-Fein E, Chiel E, Gottlieb Y, Inbar M, Ghanim M: The presence of Rickettsia is associated with increased susceptibility of Bemisia tabaci (Homoptera: Aleyrodidae) to insecticides. Pest Manag Sci 2008, 64:789-792.

22. Gottlieb Y, Ghanim M, Gueguen G, Kontsedalov S, Vavre F, Fleury F, Zchori-Fein E: Inherited intracellular ecosystem: symbiotic bacteria share bacteriocytes in whiteflies. FASEB J 2008, 22:2591-2599.

23. Hypsa V, Dale C: In vitro culture and phylogenetic analysis of "Candidatus Arsenophonus triatominarum," an intracellular bacterium from the triatomine bug, Triatoma infestans. Int J Sys Bacteriol 1997, 47:1140-1144

24. Costa HS, Westcot DM, Ullman DE, Rosell RC, Brown JK, Johnson MW: Morphological variation in Bemisia endosymbionts. Protoplasma 1995, 189:194-202

25. Bao SN, Kitajima EW, Callaini G, Dallai R: Virus-like particles and Rickettsialike organisms in male germ and cyst cells of Bemisia tabaci (Homoptera, Aleyrodidae). J Invert Pathol 1996, 67:309-311.

26. Zchori-Fein E, Gottlieb Y, Kelly SE, Brown JK, Wilson JM, Karr TL, Hunter MS: A newly-discovered bacterium associated with parthenogenesis and a change in host selection behavior in parasitoid wasps. Proc Nat/ Acad SciUSA 2001, 98:12555-12560.

27. Marzorati M, Alma A, Sacchi L, Pajoro M, Palermo S, Brusetti L, Raddadi N, Balloi A, Tedeschi R, Clementi E, Corona S, Quaglino F, Bianco PA, Beninat T, Bandi C, Daffonchio D: A novel Bacteroidetes symbiont is localized in Scaphoideus titanus, the insect vector of flavescence dorée in Vitis vinifera. Appl Environ Microbiol 2006, 72:1467-1475.

28. Bigliardi E, Sacchi L, Genchi M, Alma A, Pajoro M, Daffonchio D, Marzorati M, Avanzati AM: Ultrastructure of a novel Cardinium sp. symbiont in Scaphoideus titanus (Hemiptera: Cicadellidae). Tissue Cell 2006, 38:257-261

29. Sacchi L, Genchi M, Clementi E, Bigliardi E, Avanzati AM, Pajoro M, Negri I, Marzorati M, Gonella E, Alma A, Daffonchio D, Bandi C: Multiple symbiosis in the leafhopper Scaphoideus titanus (Hemiptera: Cicadellidae): details of transovarial transmission of Cardinium sp. and yeast-like endosymbionts. Tissue Cell 2008, 40:231-242.

30. Min KT, Benzer S: Wolbachia, normally a symbiont of Drosophila, can be virulent, causing degeneration and early death. Proc Natl Acad Sci USA 1997, 94:10792-10796

31. Ijichi N, Kondo N, Matsumoto R, Shimada M, Ishikawa H, Fukatsu T: Internal spatiotemporal population dynamics of infection with three Wolbachia strains in the adzuki bean beetle, Callosobruchus chinensis (Coleoptera: Bruchidae). Appl Environ Microbiol 2002, 68:4074-4080. 
32. Mitsuhashi W, Saiki T, Wei W, Kawakita H, Sato M: Two novel strains of Wolbachia coexisting in both species of mulberry leafhoppers. Insect Mol Biol 2002, 11:577-584.

33. Ferree PM, Frydman HM, Li JM, Cao J, Wieschaus E, Sullivan W: Wolbachia utilizes host microtubules and dynein for anterior localization in the Drosophila oocyte. PLoS Pathog 2005, 1:111-124.

34. Clark ME, Veneti Z, Bourtzis K, Karr TL: The distribution and proliferation of the intracellular bacteria Wolbachia during spermatogenesis in Drosophila. Mech Dev 2002, 111:3-15.

35. Veneti Z, Clark ME, Karr TL, Savakis C, Bourtzis K: Heads or tails: hostparasite interactions in the Drosophila-Wolbachia system. Appl Environ Microbiol 2004, 70:5366-5372.

36. Gomez-Valero L, Soriano-Navarro M, Perez-Brocal V, Heddi A, Moya A, Garcia-Verdugo JM, Latorre A: Coexistence of Wolbachia with Buchnera aphidicola and a secondary symbiont in the aphid Cinara cedri. $J$ Bacteriol 2004, 186:6626-6633.

37. Heddi A, Grenier AM, Khatchadourian C, Charles H, Nardon P: Four intracellular genomes direct weevil biology: nuclear, mitochondrial, principal endosymbiont, and Wolbachia. Proc Natl Acad Sci USA 1999, 96:6814-6819.

38. Ghanim M, Rosell RC, Campbell LR, Czosnek H, Brown JK, Ullman DE: Digestive, salivary, and reproductive organs of Bemisia tabaci (Gennadius) (Hemiptera: Aleyrodidae) B type. J Morpho/ 2001, 248:22-40.

39. Sintupachee S, Milne JR, Poonchaisri S, Baimai V, Kittayapong P: Closely related Wolbachia strains within the pumpkin arthropod community and the potential for horizontal transmission via the plant. Microb Ecol 2006, 51:294-301.

40. Chen D, Purcell AH: Occurence and transmission of facultative endosymbionts in aphids. Curr Microbiol 1997, 34:220-225.

41. Gray SM, Banerjee N: Mechanisms of Arthropod transmission of plant and animal viruses. Microbiol Mol Biol Rev 1999, 63:128-148.

42. Bigliardi E, Sacchi L, Genchi M, Alma A, Pajoro M, Daffonchio D, Marzorati M, Avanzati AM: Ultrastructure of a novel Cardinium sp. symbiont in Scaphoideus titanus (Hemiptera: Cicadellidae). Tissue Cell 2006, 38:257-261.

43. Vautrin $E$, Vavre F: Interactions between vertically transmitted symbionts: cooperation or conflict? Trends Microbio/ 2009, 17:95-99.

44. Vautrin E, Genieys S, Charles S, Vavre F: Do vertically-transmitted symbionts co-existing in a single host compete or cooperate? A modeling approach. J Evol Biol 2008, 21:145-161.

45. Chen DQ, Montllor CB, Purcell AH: Fitness effects of two facultative endosymbiotic bacteria on the pea aphid, Acyrthosiphon pisum, and the blue alfalfa aphid, A. kondoi. Entomol Exp App/ 2000, 95:315-323.

46. Darby AC, Birkle LM, Turner SL, Douglas AE: An aphid-borne bacterium allied to the secondary symbionts of whitefly. FEMS Microbiol Ecol 2001, 36:43-50

47. Tsuchida T, Koga R, Shibao H, Matsumoto T, Fukatsu T: Diversity and geographic distribution of secondary endosymbiotic bacteria in natural populations of the pea aphid, Acyrthosiphon pisum. Mol Ecol 2002, 11:2123-2135.

48. Darby AC, Tosh CR, Walters KFA, Douglas AE: The significance of a facultative bacterium to natural populations of the pea aphid Acyrthosiphon pisum. Ecol Entomol 2003, 28:145-150

49. Haynes S, Darby AC, Daniell TJ, Webster G, Van Veen FJF, Godfray HCJ, Prosser JI, Douglas AE: Diversity of bacteria associated with natural aphid populations. Appl Environ Microbiol 2003, 69:7216-7223.

50. Ferrari J, Darby AC, Daniell TJ, Godfray HCJ, Douglas AE: Linking the bacterial community in pea aphids with host-plant use and natural enemy resistance. Ecol Entomol 2004, 29:60-65.

51. Wernegreen JJ: Endosymbiosis: lessons in conflict resolution. PLOS Biol 2004, 2:307-311.

52. Von Dohlen CD, Kohler S, Alsop ST, McManus WR: Mealybug $\beta$ proteobacterial endosymbionts contain $\gamma$-proteobacterial symbionts. Nature 2001, 412:433-436.

53. Perlman SJ, Hunter MS, Zchori-Fein E: The emerging diversity of nonpathogenic Rickettsia. Proc Royal Soc London B 2006, 27:2097-2106.

54. Hunter MS, Zchori-Fein E: Bacteroidetes as insect symbionts. In Insect Symbiosis // Edited by: Bourtzis K, Miller T. Florida: CRC Press; 2006:39-56.

55. Perotti MA, Clarke HK, Turner BD, Braig HR: Rickettsia as obligate and mycetomic bacteria. FASEB J 2006, 20:E1646-E1656.
56. De Barro PJ, Scott KD, Graham GC, Lange CL, Schutze MK: Isolation and characterization of microsatellite loci in Bemisia tabaci. Mol Ecol Notes 2003, 3:40-43.

57. Frohlich DR, Torres-Jerez I, Bedford ID, Markham PG, Brown JK: A phylogeographical analysis of the Bemisia tabaci species complex based on mitochondrial DNA markers. Mol Ecol 1999, 8:1683-1691.

58. Matalon Y, Katzir N, Gottlieb Y, Portnoy V, Zchori-Fein E: Cardinium in Plagiomerus diaspidis (Hymenoptera: Encyrtidae). J Invertebr Pathol 2007, 96:106-8.

doi: 10.1186/1471-2180-10-142

Cite this article as: Skaljac et al., Co-infection and localization of secondary symbionts in two whitefly species BMC Microbiology 2010, 10:142

\section{Submit your next manuscript to BioMed Centra and take full advantage of:}

- Convenient online submission

- Thorough peer review

- No space constraints or color figure charges

- Immediate publication on acceptance

- Inclusion in PubMed, CAS, Scopus and Google Scholar

- Research which is freely available for redistribution
C Biomed Central 